frequency of the atoms (or molecules) on their mean distance apart more exactly than this has been done by the above authors, but also to take into account the gradual amorphisation of the body, which begins long before the melting point is reached. This 'amorphisation' can be regarded as the result of a large number of local and temporary ruptures of the body, due to the increase of the interatomic distances. To make this point clear, let us imagine that three atoms are put in a line and the distance apart between the two end atoms is gradually increased. Then the middle atom, which in a state of lowest energy should at the beginning lie just midway its neighbours, will finally move towards one of them, since the middle position, which initially corresponded to a minimum of the potential energy, will finally correspond to its maximum. The same result as that due to external forces, pulling the end atoms in opposite directions, must be produced by heat motion. To compare the two effects, however, we must consider not the average distances between the atoms as determined by the thermal expansion, but the maximum distances connected with thermal oscillations. It can thus easily be shown that a one-dimensional crystal with increase of temperature will not 'melt' but will break up into a number of small pieces (single atoms and doublets). In a two- or three-dimensional solid, a local 'rupture', however, will not lead to a breaking up of the whole body, thanks to the existence of lateral bonds between the atoms.

Although such local and temporary ruptures must take place also in a solid body, their number and importance greatly increase on melting, which accounts for the very much larger degree of 'amorphisation' which is found in the liquid state. This explains also the fact, first noticed by Rashevksy', that the latent heat of fusion is of the same order of magnitude as the elastic energy of the corresponding body strained to its theoretical breaking point at the zero point of temperature.

We thus see that the three states of aggregation of matter-the solid, liquid and gaseous-must be regarded as forming one continuous sequence, the sharp transition points-melting or boiling-being simply substitutes for continuous transitions through unstable intermediate states, corresponding to the hook-like parts of the $p-v$ curve. At ordinary temperatures there are two such hooklike portions, the first one (for smaller $v$ 's) corresponding to the melting, and the second to the boiling point. Above a certain temperature $T_{1}-$ the ordinary critical temperature of the substance -the second hook disappears, whereas the first one remains, since, as has been shown by Bridgman, and especially by Simon, it is possible to obtain under sufficiently high pressure a substance in the solid state above its critical temperature. A critical temperature $T_{\mathrm{2}}>T_{1}$ for which the first hook should also disappear does not exist (according to Bridgman the melting temperature displays a monotonic rise with increasing pressure). It is, however, very probable that there exists a critical temperature $T_{0} \leqslant T_{1}$ (connected with a strongly negative value of the pressure) at and below which the first hook should disappear-corresponding to the fusion of the solid and liquid states into a single 'condensed' state.

A detailed mathematical treatment of the above questions will appear shortly elsewhere (in the Jour. Phys., or the Acta Phisicochimica USSR).

\footnotetext{
1. J. Frenkel, Uber die Wärmebewegung in festen und flïsslgen Körpern, Z. Phys, p. 1, 1926. P. Debye, Z. Phys., Feb. 1, 1935.

A similar view has been expressed by the writer in a book on the "Theory of the Solid and Liquid States" (in Russian).

cf. S. Frenkel, loc. cit.

Phys. Rev., Dec. 1934.

- Z. Phys., 1927.
}

\title{
Human Origin and Christian Doctrine
}

\author{
By Dr. W. D. Lang, F.R.S.
}

\begin{abstract}
THE late Bishop Gore remarks, in his "Belief In God", that it is not so much about the existence of God that men dispute, as the nature of the God in whom they can believe. Sir Ambrose Fleming, in the second published edition of his presidential address to the Victoria Institute, on "Modern Anthropology versus Biblical Statements on Human Origin", takes a less tolerant view. In his belief, as he states it, that "adherence to the doctrine of [organic] evolution is entirely incon-
\end{abstract}

sistent with belief in the fundamental doctrines of Christianity . . .", he appears rather to embrace in one atheistical category all who do not subscribe to this belief; such, at least, is the irresistible impression one receives on reading his address. This premise, which at best can have but an individual, and not a general, application, will be further considered: but first, all who admit the transmutation of species-and they are a heterogeneous assemblage, and must include, besides 
modernist churchmen, churchmen as orthodox as Bishop Gore, educated laymen, Christian and nonChristian, agnostics, atheists, and even early churchmen like St. Augustine-must settle down together and consider the rest of Sir Ambrose's discourse.

Two main themes, like the narratives in the early chapters of Genesis, run through the thesis, namely, the inadequacy of palæontology in general, and of anthropological palæontology in particular, to prove the transmutation of species ; and the inadequacy of natural selection as a means of transmuting species. It is clear that, if the first point is admitted and the transmutation of species is thereby considered as disproved, it is meaningless to labour the second ; yet both points are laboured, though somewhat intermingled, in a series of arguments, from which, perhaps, one on each point stands out more emphatically than the rest. If, says Sir Ambrose, in effect, transmutation of species has taken place, transitional forms would be commoner than they are; and he points especially to the few known remains of supposed man more primitive than Homo sapiens. It is probable that those who have had most experience of fossils, both in the field and in the study, would say that, considering the long succession of fauna after world-wide fauna presented to palæontologists, considering the comparatively few accessible exposures of rocks of any one age in the world, considering the small chances of any organism of any given age being preserved as a fossil, and, comparatively speaking, the very small amount of intensive and extensive collecting that has been done, it is wonderful how notably fossil species are found to intergrade ; and they would probably agree that all the evidence points to there having been a transmutation of species. The chances against any organism, and especially a bony organism, being preserved as a fossil, also tells against Sir Ambrose's contention that the associated remains of Pithecanthropus and Eoanthropus do not belong, respectively, to one individual.

Again, Sir Ambrose argues that the apparent rate of increase in the population of the world is a datum for estimating the age of the human species; and he holds that thus it can be proved that the inconceivably long periods demanded by the Darwinians for the evolution of man are impossible. He does not accept the contention of Malthus and Darwin that populations are equilibrated by their environment, and that once the bands of a controlling environment are loosed, even the slowest-breeding species will increase by leaps and bounds-a supposition which is corroborated by observing the sudden and immense fluctuations in some recent animal populations, human races included, the causes of which, if not understood, are almost certainly environmental in the widest sense of that term. Were this not so, the whole world must have been filled with human inhabitants again and again, even in the comparatively short time allowed by Sir Ambrose Fleming since man's creation.

This ground has, however, been gone over many' times; nor does it go to the root of Sir Ambrose Fleming's difficulties, as is clear from the following passage :

"In rejecting the idea of Creation by Divine Will and Power, the evolutionist then claims that the only kind of beginning which can be accepted as true is one which appeals to his own finite intelligence. $\mathrm{He}$ is prepared to accept the Darwinian hypothesis because it is intelligible to him. ... He rejects as untrue any statements about Nature which lie outside the limits of present human understanding and experience. ... Thus, said an eminent naturalist, . . . 'the theory of evolution was a theory universally accepted, not because it could be proved to be true but because the only alternative, special creation, was clearly incredible" ".

Surely this passage goes to the heart of the matter, and reveals a misappreciation both on the part of Sir Ambrose and of his supposed opponents of the self-limitation of science. If it is true to say that a science is a marshalling of observed facts (a natural science, of observed physical facts) with the view of drawing logical inductions from them, it is clear that a natural science is selflimited, in its material (observed facts), in its method (logic), and in its standards (physical values). It must proceed from immediate effects to proximate causes, and so feels its way back to origins. It 'explains' the end by the beginning. It is otherwise with philosophy, which has its scientific aspect, and in this light might be called the science of significancies; but its material is all experience, and its standards are metaphysical values. It does not 'explain' the end by seeking its origin, but believes that the end 'explains' the beginning.

It is clear that, in the passage quoted above, Sir Ambrose Fleming is standing on metaphysical ground, and when he complains that his opponents reject "any statements about Nature which lie outside the limits of present human understanding . . ." he is really expecting them, as natural scientists, to go beyond the limits imposed by their system. They should answer that they must play the game, and seek proximate causes before they can feel back to ulterior causes, least of all adduce an ultimate cause. When, moreover, he points out that their arguments do not prove an anthropoid origin for man, they would answer 
that such a biological theory, by its very nature, is incapable of mathematical proof, but must depend, like most such questions, on a balance of probabilities ; and that is what Prof. Watson meant, in the passage quoted by Sir Ambrose, in saying that special creation was incredible. On the other hand, Sir Ambrose would be right in claiming that, as natural scientists, they are incompetent, through the very limitations of their method, to disprove the existence of God. In other words, Sir Ambrose and his opponents speak different languages, and on terms on which agree. ment is impossible.

We are thus brought back to Sir Ambrose's premise, that the acceptance of the doctrine of organic evolution is entirely inconsistent with the fundamental doctrines of Christianity. But, in complete sympathy with his ultimate conclusions, with genuine respect for his courage in upholding them, and in no self-complacent or dogmatic spirit, a Christian may yet ask what clause in the Christian creeds forbids him to be an evolutionist ? Why may not a Christian believe, with the early Church, that the story in Genesis of man's creation is focused upon the spiritual truth that God created man, and is not to be regarded as a scientific account of the process? Why, if he honestly follows intellectual truth, may he not trust God not to lead him to intellectual confusion; and, although he cannot expect to solve all his intellectual difficulties, just because, as Sir Ambrose insists, his mind is finite, why may he not hope, like Job in similar circumstances, ultimately to gain a vision of God?

After all, what differentiates a Christian is what he thinks of the person of Christ, and this seems to bear but remotely upon the physical processes of creation. On this criterion, it must be admitted that the greatest evolutionist cannot be claimed as a Christian-" I gradually came," Darwin said, "to disbelieve in Christianity as a divine revelation"; on the other hand, he repudiated atheism. His life, however, largely belied the statement just quoted. For the Christian's God is also eminently expressed in all that is beautiful, good and true. Now, on his own showing, Darwin gradually lost his æsthetic faculty, as he gradually lost his Christian faith; but every page of his writings expresses that wide charity which is the hall-mark of goodness; while his life was a single-minded pursuit of truth. Surely, Sir Ambrose will allow that such a man, although an evolutionist and in spite of his disavowing Christianity, is yet not far from the Kingdom of God.

\section{Poison Gas}

$\mathrm{T}^{\mathrm{H}}$ HE menace to civilisation of attacks on cities from the air is naturally perturbing all the peoples of Europe, for it is generally agreed by those best able to judge that there is no effective means of defence, so that the attacked country would be obliged to retaliate on the cities of the aggressor. It is true that the use of gas in war was prohibited by the Geneva Gas Protocol of 1925 , to which most of the principal powers of the world subscribed; but in view of the failure to effect general disarmament there is even less confidence in the protocol now than there was in 1925. The attack might be made by dropping bombs filled with high explosive, or incendiary composition or with gas, or gas might be sprayed. In the Great War gas was not used in this way, and consequently it is not possible to say from actual experience whether it would be more effective than high explosive.

Against troops who had been trained in the use of gas masks and other protective measures the statistics, so far as they go, indicate that gas shells cause about as many casualties as the same number of H.E. shells, but that they kill far fewer.
The civilian population of a city could not be trained in protective measures to the same extent, and a large proportion would not have gas masks; but, on the other hand, they can take refuge in the houses, and so it should be possible to restrict the casualties. So far as can be judged in the absence of actual experience, these should be considerably less than those which would be caused by an equal weight of H.E. bombs. Probably the greatest damage, both physical and moral, would be done by squadrons of low-flying planes spraying gas followed immediately by others dropping H.E. bombs. If such an attack were delivered on a day when there were low clouds above which the approach could be made, and into which the attackers could dash again after the assault, it would not be possible for the defending fighting planes and anti-aircraft guns to accomplish much against them. If air raids should be made again in the future, they would, of course, be on a vastly greater scale than in the War. Consequently, it would be more possible to produce a lethal concentration of gas over such a large area as is needed for a decided military effect. 